\title{
Changes in photosynthesis, chloroplast ultrastructure, and antioxidant metabolism in leaves of sorghum under waterlogging stress
}

\author{
R.D. ZHANG ${ }^{*, * *}$, Y.F. ZHOU ${ }^{*,+}$, Z.X. YUE ${ }^{* *}$, X.F. CHEN*, X. CAO ${ }^{* *}$, X.X. XU*, Y.F. XING*, B. JIANG*, \\ X.Y. AI*, and R.D. HUANG* \\ College of Agronomy, Shenyang Agricultural University, Shenyang, Liaoning, China* \\ Institute of Cash Crops, Shanxi Academy of Agricultural Sciences, Taiyuan, Shanxi, China**
}

\begin{abstract}
Waterlogging limits plant growth and yield. We investigated the effects of waterlogging stress on leaf photosynthesis, chlorophyll fluorescence, antioxidant capacity, chloroplast ultrastructure, and yield of sorghum (Sorghum bicolor L.). Two sorghum cultivars, Jinuoliang01 (JN01, waterlogging-tolerant cultivar) and Jinza31 (JZ31, waterlogging-sensitive cultivar) were subjected to a 12-d waterlogging treatment; the plants of the two cultivars which were not subjected to waterlogging were used as control (CK), respectively. After waterlogging treatment, the yield of JZ31 and JN01 decreased by 72.3 and $52.9 \%$, the net photosynthetic rate of JZ31 and JN01 decreased by 61.8 and 39.0\%, respectively, compared with CK. The chlorophyll content was higher, PSII was more stable, and chloroplast structure remained more intact in JN01 than that in JZ31 under waterlogging. This was due to the higher peroxidase and catalase activities and nonphotochemical quenching in JN01 compared to JZ31. Therefore, greater antioxidant capacity and nonphotochemical quenching could alleviate damage to PSII and chloroplast ultrastructure to maintain higher net photosynthetic rate under waterlogging. This may be an important waterlogging-tolerance mechanism of sorghum.
\end{abstract}

Additional key words: gas-exchange parameters; malondialdehyde; photosynthetic apparatus; physiology.

\section{Introduction}

Some studies have predicted that global climate change will increase the frequency and amount of precipitation and waterlogging will become a more serious problem worldwide (Wright et al. 2017). Waterlogging limits plant growth and development, resulting in a reduction in grain yield for crops in Asia and many other parts of the world (Setter and Waters 2003). It is estimated that 10\% of irrigated areas are affected by waterlogging, which can decrease crop production by up to $20 \%$ (Shabala 2011). The areas most prone to waterlogging are low-lying areas with poor drainage. Because sorghum is strongly stress resistant, it is usually grown on marginal lands such as riparian fields or low-lying areas. When these areas are affected by heavy rainfall or overflow, sorghum is subjected to waterlogging stress. Waterlogging severely restrains sorghum growth and significantly decreases its yield (Promkhambut et al. 2010). Thus, it is desirable to plant waterlogging-tolerant sorghum cultivars in these regions.
Waterlogging leads to various changes in the morphology, physiology, and anatomical structure of crop plants (Arguello et al. 2016, Herzog et al. 2016, Zhang et al. 2016). Photosynthesis is sensitive to waterlogging. Waterlogging usually causes stomatal closure, thereby preventing gas exchange and decreasing the photosynthetic rate (Pereira et al. 2014, Yu et al. 2015, Zhu et al. 2016). Promkhambut et al. (2010) reported that a long-term waterlogging caused a great reduction in the biomass production of sweet sorghum due to reduced $P_{\mathrm{N}}, g_{\mathrm{s}}$, and $E$. Waterlogging can also result in decreased activity of photosynthetic enzymes (Lin et al. 2016), changes in chloroplast structure (Ren et al. 2016), damage to the photosynthetic reaction center (Zheng et al. 2009), and decreased chlorophyll (Chl) content (Bansal and Srivastava 2015). These nonstomatal factors severely inhibit photosynthesis under waterlogging. In addition, PSII is impaired and its maximum photochemical efficiency, represented by $\mathrm{F}_{\mathrm{v}} / \mathrm{F}_{\mathrm{m}}$, is decreased under waterlogging (Shao et al. 2013). This affects electron transport and changes the amount of light energy directed into organic synthesis, resulting in

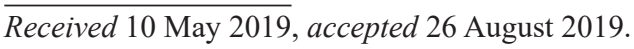

${ }^{+}$Corresponding author; e-mail: zhouyufei2002@aliyun.com, zhouyufei@syau.edu.cn

Abbreviations: CAT - catalase; $\mathrm{Chl}$ - chlorophyll; $C_{\mathrm{i}}$ - intercellular $\mathrm{CO}_{2}$ concentration; $E$ - transpiration rate; ETR - electron transport rate; $\mathrm{F}_{0}$ - minimal fluorescence; $\mathrm{F}_{0}{ }^{\prime}$ - minimal fluorescence of the light-adapted state; $\mathrm{F}_{\mathrm{m}}$ - maximal fluorescence; $\mathrm{FM}$ - fresh mass; $\mathrm{F}_{\mathrm{m}}{ }^{\prime}-$ maximal fluorescence of the light-adapted state; $\mathrm{F}_{\mathrm{s}}$ - steady state fluorescence yield; $\mathrm{F}_{\mathrm{v}} / \mathrm{F}_{\mathrm{m}}-$ maximum photochemical efficiency of PSII; $g_{\mathrm{s}}$ - stomatal conductance; MDA - malondialdehyde content; NPQ - nonphotochemical quenching; $P_{\mathrm{N}}$ - net photosynthetic rate; POD - peroxidase; $\mathrm{q}_{\mathrm{P}}$ - photochemical quenching coefficient; ROS - reactive oxygen species; SOD - superoxide dismutase; WL - waterlogging; $\Phi_{\text {PSII }}$ - effective quantum yield of PSII photochemistry.

Acknowledgments: This work was supported by the earmarked fund for the China Agriculture Research System (CARS-06).
} 
lowered effective quantum yield of PSII photochemistry $\left(\Phi_{\text {PSII }}\right)$, lower electron transport rate (ETR), and a lower photochemical quenching coefficient $\left(\mathrm{q}_{\mathrm{P}}\right)$ value (Mathobo et al. 2017). Ultimately, waterlogging restrains photosynthesis, decreases biomass accumulation, and reduces grain yield. However, very little is known about photosynthetic characteristics in sorghum under waterlogging stress from the perspective of activities of PSII and chloroplast ultrastructure.

Chloroplasts are important reaction sites of photosynthesis and their structures are sensitive to abiotic stress (Zhao et al. 2001, Shao et al. 2016). Previous studies have reported that waterlogging results in the destruction of chloroplast structure (Ren et al. 2016, Zhou et al. 2018). Chloroplasts are the main source of reactive oxygen species (ROS) and are easily attacked by excess ROS (Luan et al. 2018). To alleviate oxidative stress, plants have evolved a series of mechanisms to reduce ROS accumulation. Redundant electrons in the photosynthetic electron transport chain can be dissipated via the xanthophyll cycle, which protects the photosynthetic center against destruction by excess energy (Jahns and Holzwarth 2012). Plant cells also have an enzymatic antioxidant system comprising superoxide dismutase (SOD), peroxidase (POD), and catalase (CAT). This antioxidant system can efficiently reduce the ROS contents, thereby protecting cells from oxidative injury. Some studies have shown that the activity of antioxidant enzymes can increase under waterlogging (Yin et al. 2009), while others have found decreased antioxidant enzyme activity in waterlogged plants (Tan et al. 2008). Thus, the capacity to scavenge ROS, the dynamic pattern of ROS generation during waterlogging, and their relationship with photosynthesis are areas of interest.

The aim of this study was to explore the changes in sorghum under waterlogging stress, and the relationship between photosynthesis and antioxidant metabolism. We evaluated changes in photosynthetic characteristics, Chl fluorescence, antioxidant enzyme activity, and chloroplast ultrastructure in waterlogging-resistant and waterloggingsensitive cultivars during and after a waterlogging treatment. The results of this study illustrate the changes in photosynthesis and antioxidant activity in sorghum cultivars with different degrees of waterlogging resistance. These results may be used to develop a functional approach to improve the performance of sorghum under waterlogged conditions.

\section{Materials and methods}

Experimental design: The experiment was carried out in 2017 at the Shenyang Agricultural University, China. The experimental materials were cultivars that are currently cultivated in China. We screened and identified sorghum cultivars in 2016, and a comprehensive evaluation of agronomic characteristics showed that JN01 is a waterlogging-tolerant cultivar and JZ31 is waterloggingsensitive cultivar. These two cultivars were used as the experimental materials in this study. On 10 May, seeds of both cultivars were sown in pots $(0.30 \mathrm{~m}$ high, $0.33 \mathrm{~m}$ in diameter). Each pot had three holes in the bottom to allow drainage of excessive water. Each pot was filled with $19 \mathrm{~kg}$ of soil. The soil was loam with the following properties: $30.82 \mathrm{~g}$ (organic matter) $\mathrm{kg}^{-1}, 114.52 \mathrm{mg}$ (alkali-hydrolysable nitrogen) $\mathrm{kg}^{-1}, 8.94 \mathrm{mg}$ (available phosphorus) $\mathrm{kg}^{-1}$, and $102.93 \mathrm{mg}$ (available potassium) $\mathrm{kg}^{-1}$. There were four treatments: (1) CK-JN01: JN01 was well-watered; (2) CK-JZ31: JZ31 was well-watered; (3) WL-JN01: JN01 suffered from waterlogging stress; (4) WL-JZ31: JZ31 suffered from waterlogging stress. The experiment had a completely randomized design. The pots were randomly placed in the field. The seedlings' shoots had emerged by 17 May and were thinned to one plant per pot. The waterlogging treatments were started on 20 June, when all plants had five fully expanded leaves. Each pot containing a sorghum plant was placed in another pot without holes in the bottom and the water level was maintained at $3 \mathrm{~cm}$ above the soil surface. The two cultivars had its own control (CK); the CK group was irrigated normally and kept the soil moisture at $75-80 \%$ of saturated water-holding capacity with soil moisture meter (TDR100, Spectrum, USA). Each treatment had 30 replicates. At 0, 3, 6, 9, and $12 \mathrm{~d}$ of the waterlogging treatment, the photosynthetic and physiological parameters were measured.

Gas-exchange parameters were measured using $L I-6400$ portable photosynthesis system (LI-COR Inc., Lincoln, NE, USA). On each plant, a new fully expanded leaf was selected and marked for measuring gas-exchange parameters before the waterlogging treatment. The gasexchange rate was measured in a controlled chamber $(2 \times 3 \mathrm{~cm})$ in which the $\mathrm{CO}_{2}$ concentration was $385 \pm 5 \mu \mathrm{mol} \mathrm{mol}^{-1}$ and the relative humidity was $65 \pm 3 \%$, with PPFD of $1,600 \mu \mathrm{mol} \mathrm{m} \mathrm{m}^{-2} \mathrm{~s}^{-1}$. The net photosynthetic rate $\left(P_{\mathrm{N}}\right)$, transpiration rate $(E)$, stomatal conductance $\left(g_{\mathrm{s}}\right)$, and intercellular $\mathrm{CO}_{2}$ concentration $\left(C_{\mathrm{i}}\right)$ were measured at the same time at 3-d intervals during the waterlogging treatment. All measurements were conducted between 10:00-11:00 h local time.

Chl fluorescence parameters were measured using a Junior-PAM portable chlorophyll fluorescence meter (Walz, Effeltrich, Germany), which was connected to a computer with WinControl-3 software for processing data. The measurement method was that described by Hazrati et al. (2016), and measurements were conducted on the same leaf used to measure gas-exchange parameters. Before measurement, the leaf was dark-adapted for $30 \mathrm{~min}$. The minimal fluorescence $\left(\mathrm{F}_{0}\right)$ was measured under very low light $\left[<0.1 \mu \mathrm{mol}\right.$ (photon) $\left.\mathrm{m}^{-2} \mathrm{~s}^{-1}\right]$. The maximal fluorescence $\left(\mathrm{F}_{\mathrm{m}}\right)$ was measured under a saturation pulse $\left[10,000 \mu \mathrm{mol}\left(\right.\right.$ photon) $\mathrm{m}^{-2} \mathrm{~s}^{-1}$, pulse time of $\left.0.7 \mathrm{~s}\right]$. The minimal fluorescence of the light-adapted state $\left(\mathrm{F}_{0}{ }^{\prime}\right)$, the maximal fluorescence of the light-adapted state $\left(\mathrm{F}_{\mathrm{m}}{ }^{\prime}\right)$ and the steady-state fluorescence yield $\left(\mathrm{F}_{\mathrm{s}}\right)$ were measured after the leaf was adapted to actinic light $[800 \mu \mathrm{mol}$ (photon) $\mathrm{m}^{-2} \mathrm{~s}^{-1}$ ] for $15 \mathrm{~min}$. The $\mathrm{Chl}$ fluorescence parameters were calculated according to Van Kooten and Snel (1990), as follows: photochemical efficiency of PSII, $\mathrm{F}_{\mathrm{v}} / \mathrm{F}_{\mathrm{m}}=$ $\left(\mathrm{F}_{\mathrm{m}}-\mathrm{F}_{0}\right) / \mathrm{F}_{\mathrm{m}}$, effective quantum yield of PSII photo- 
chemistry, $\Phi_{\mathrm{PSII}}=\left(\mathrm{F}_{\mathrm{m}}{ }^{\prime}-\mathrm{F}_{\mathrm{s}}\right) / \mathrm{F}_{\mathrm{m}}{ }^{\prime}$, photochemical quenching coefficient, $\mathrm{q}_{\mathrm{P}}=\left(\mathrm{F}_{\mathrm{m}}{ }^{\prime}-\mathrm{F}_{\mathrm{s}}\right) /\left(\mathrm{F}_{\mathrm{m}}{ }^{\prime}-\mathrm{F}_{0}{ }^{\prime}\right)$, and nonphotochemical quenching, $N P Q=\left(F_{m}-F_{m}{ }^{\prime}\right) / F_{m}{ }^{\prime}$.

Pigment extraction and quantification: Chl content was measured according to Lichtenthaler (1987). Fresh leaf material $(0.2 \mathrm{~g})$ from a fully expanded leaf, excluding main veins, was cut into small pieces with scissors. The leaf pieces were immersed in alcohol $(96 \%, \mathrm{v} / \mathrm{v})$ and kept at $4^{\circ} \mathrm{C}$ and in the dark until the leaf color became white. The absorbance of the extract was determined at 649 and $665 \mathrm{~nm}$ using a UV-spectrophotometer (Hitachi $U V-1800$, Kyoto, Japan). The contents of Chl $a$, Chl $b$, and $\mathrm{Chl}(a+b)\left[\mathrm{mg} \mathrm{g}^{-1}(\mathrm{FM})\right]$ were calculated using the following equations: $\mathrm{Chl} a=\left[\left(12.72 \mathrm{~A}_{665}-2.59 \mathrm{~A}_{649}\right) \times \mathrm{V}\right] /$ $(1,000 \times \mathrm{M}), \mathrm{Chl} b=\left[\left(22.88 \mathrm{~A}_{649}-4.687 \mathrm{~A}_{665}\right) \times \mathrm{V}\right] /$ $(1,000 \times \mathrm{M}), \mathrm{Chl}(a+b)=\mathrm{Chl} a+\mathrm{Chl} b$, where $\mathrm{A}_{\lambda}$ is the absorbance at the specific wavelength, $\mathrm{V}$ is the volume of the extraction liquid, and $\mathrm{M}$ is the mass of the sample.

Malondialdehyde content (MDA) and enzyme activity assays: The leaves used for MDA and enzyme activity assays were the same as those used to measure gasexchange and Chl fluorescence parameters. The leaves were harvested, frozen in liquid nitrogen, and then stored at $-80^{\circ} \mathrm{C}$ until analysis.

The MDA was determined according to Zhang et al. (2007). Leaf tissue $(0.5 \mathrm{~g})$ was homogenized in $5 \mathrm{ml}$ of trichloroacetic acid $(5 \%, \mathrm{v} / \mathrm{v})$ and centrifuged at 5,000 $\times g$ for $20 \mathrm{~min}$ at $4{ }^{\circ} \mathrm{C}$. The supernatant $(1.5 \mathrm{~mL})$ was mixed with $2.5 \mathrm{~mL}$ of $5 \%$ trichloroacetic acid containing $0.5 \%$ 2-thiobarbituric acid, and the mixture was heated at $100^{\circ} \mathrm{C}$ for $15 \mathrm{~min}$. The reaction mixture was cooled to room temperature and then centrifuged at $5,000 \times g$ for $10 \mathrm{~min}$. The absorbance of the supernatant was determined at 532 and $600 \mathrm{~nm}$ with a UV-spectrophotometer (Hitachi $U V-1800$, Kyoto, Japan).

For enzyme activity assays, leaf samples $(0.5 \mathrm{~g})$ were ground with a mortar and pestle in $5 \mathrm{~mL}$ of phosphate buffer $(0.05 \mathrm{mM}, \mathrm{pH} 7.5)$ containing $0.05 \mathrm{mM}$ EDTA and $2 \%(\mathrm{w} / \mathrm{v})$ insoluble polyvinyl pyrrolidone. The homogenate was centrifuged at $1,000 \times g$ for $20 \mathrm{~min}$ at $4^{\circ} \mathrm{C}$. The supernatant was used to measure enzyme activities.

The SOD (EC 1.15.1.1) activity was measured following the method of Yin et al. (2009). The 3-mL reaction mixture contained $130 \mathrm{mM}$ methionine (Met), $75 \mu \mathrm{M}$ nitroblue tetrazolium chloride (NBT), 2.0 $\mu \mathrm{M}$ riboflavin, $50 \mathrm{mM}$ phosphate buffer ( $\mathrm{pH} 7.8$ ), and $0.1 \mathrm{ml}$ of enzyme extract. The reaction mixture was exposed to light $\left[600 \mu \mathrm{mol}\right.$ (photon) $\mathrm{m}^{-2} \mathrm{~s}^{-1}$ ] for $20 \mathrm{~min}$. The control was kept in the dark. The photoreduction of NBT was monitored by measuring absorbance at $560 \mathrm{~nm}$. One unit of SOD was defined as the amount that inhibited the photoreduction NBT by $50 \%$ under these conditions. Activity is expressed as units per gram fresh mass.

The POD (EC 1.11.1.7) activity was measured as described by Fielding and Hall (1978). The reaction mixture $(3 \mathrm{~mL})$ contained $100 \mathrm{mM}$ phosphate buffer (pH 6.0), 0.25\% (v/v) guaiacol, $3 \mathrm{mmol} \mathrm{L}^{-1}$ hydrogen peroxide, and $0.1 \mathrm{~mL}$ of enzyme extract. The change in absorbance at $470 \mathrm{~nm}$ was recorded at 1-min intervals for $3 \mathrm{~min}$. The activity of POD was calculated using the extinction coefficient of $26.6 \mathrm{mM}^{-1} \mathrm{~cm}^{-1}$ and expressed as $\mu \mathrm{mol} \mathrm{g} \mathrm{g}^{-1}$ (FM) $\mathrm{min}^{-1}$.

The CAT (EC 1.11.1.6) activity was measured as described by Yordanova et al. (2004). The reaction mixture (3 $\mathrm{mL})$ contained $100 \mathrm{mM}$ potassium phosphate buffer ( $\mathrm{pH} 7.0$ ), $10 \mathrm{mM} \mathrm{H}_{2} \mathrm{O}_{2}$, and $0.1 \mathrm{~mL}$ of enzyme extract. Changes in absorbance at $240 \mathrm{~nm}$ were recorded at 1-min intervals for $3 \mathrm{~min}$. The activity of CAT was calculated using the extinction coefficient of $39.4 \mathrm{mM}^{-1} \mathrm{~cm}^{-1}$ and expressed as $\mu \mathrm{mol} \mathrm{g} \mathrm{g}^{-1}(\mathrm{FM}) \mathrm{min}^{-1}$.

Chloroplast morphology and ultrastructure: The leaves used to measure gas exchange and $\mathrm{Chl}$ fluorescence parameters in each treatment were selected to observe chloroplast ultrastructure. Using a sharp blade, a piece $(1 \times 2 \mathrm{~mm})$ was cut from the middle of each leaf, avoiding a central vein. The leaf piece was immersed in phosphate buffer (PBS, $0.1 \mathrm{~mol} \mathrm{~L}^{-1}, \mathrm{pH}$ 6.8), containing $2 \%$ paraformaldehyde and $2.5 \%$ glutaraldehyde $(\mathrm{v} / \mathrm{v})$. The sample was degassed to allow the buffer to infiltrate into the gaps between cells. Each fixed sample was rinsed three times with PBS, and then post-fixed with osmic acid $(1 \%)$ for $2 \mathrm{~h}$. Then the sample was dehydrated in an ethanol series $(50,70,80,90$, and $100 \%)$. Finally, the sample was washed with a tert-butanol and ethanol mixture $(1: 1, \mathrm{v} / \mathrm{v})$ for $15 \mathrm{~min}$ and then embedded in Epon 812 resin (Shell Chemical Co., New York, USA). Sections were cut with an $L K B-V$ ultramicrotome ( $L K B$, Bromma, Sweden) and then stained with uranium acetate-lead citrate. Samples were observed under a transmission electron microscope (HT7700, Hitachi, Japan) at different magnifications at $100 \mathrm{kV}$.

Grain yield: After the seeds ripened, the number of panicles was counted. Ten panicles were harvested from every treatment to measure the numbers of grains per panicle and the 1,000-grain mass.

Statistical analyses: Data were analyzed by one-way analysis of variance (ANOVA) and Duncan's multiple range test using SPSS 18.0 software (SPSS Inc., Chicago, USA). Results are expressed as means \pm standard deviation (SD). Plotting was performed using Origin 8.0 software (OriginLab, Massachusetts, USA).

\section{Results}

Yield: The yields of both sorghum cultivars decreased after being subjected to a 12-d waterlogging treatment at the fiveleaf stage. Compared to JN01, JZ31 was more sensitive to waterlogging. Compared with $\mathrm{CK}, \mathrm{JZ3} 1$ and JN01 showed 72.3 and $52.9 \%$ decrease in yield, respectively. Waterlogging also affected yield components. The number of grains per panicle was most sensitive to waterlogging, showing 62.7 and $60.0 \%$ decrease in JZ31 and JN01, respectively, compared with $\mathrm{CK}$. The 1,000-grain mass also differed between the two cultivars. The 1,000-grain mass declined by $25.7 \%$ in JZ31 compared with CK, but that of JN01 was 1.2-fold that of CK. The number 
of panicles did not differ significantly between the two cultivars or between the waterlogging treatment and CK (Table 1).

Gas-exchange parameters: As shown in Fig. $1 A$, the $P_{\mathrm{N}}$ declined rapidly in both cultivars during the waterlogging treatment, as compared with the $\mathrm{CK}$, and declined to a greater extent in JZ31 than that in JN01. At the end of the waterlogging treatment, the $P_{\mathrm{N}}$ decreased by 61.8 and $39.0 \%$ in JZ31 and JN01, respectively, compared with CK. The changes in $E$ and $g_{\mathrm{s}}$ showed similar trends. Both of these parameters decreased in both cultivars during the waterlogging treatment. The $E$ and $g_{\text {s }}$ decreased more rapidly in JZ31 than that in $\mathrm{JN} 01$. At $12 \mathrm{~d}$, the $E$ and $g_{\text {s }}$ were reduced by 38.8 and $64.7 \%$, respectively, in JZ31, and by 26.7 and $39.3 \%$, respectively, in JN01 (Fig. 1B,C). The $C_{\mathrm{i}}$ first decreased and then increased in both cultivars. At $12 \mathrm{~d}$, the $C_{\mathrm{i}}$ in JZ31 and JN01 was 1.24- and 1.16-fold of that in $\mathrm{CK}$, respectively (Fig. $1 D$ ).

Chl content: In both cultivars, the Chl content was significantly reduced by the waterlogging treatment, and showed the lowest values at $12 \mathrm{~d}$ of the waterlogging treatment. Compared with CK, JZ31 showed 11.2, 43.8, 55.4, and 60.8\% decreases in Chl content at 3, 6, 9, and $12 \mathrm{~d}$ of the waterlogging treatment, respectively. Compared with CK, JN01 showed 9.5, 20.9, 34.1, and 41.3\% decreases in Chl content at 3, 6, 9, and $12 \mathrm{~d}$, respectively (Fig. 2).

Chl fluorescence parameters were significantly affected by waterlogging in both cultivars. The lowest values for $\mathrm{F}_{\mathrm{v}} / \mathrm{F}_{\mathrm{m}}, \Phi_{\mathrm{PSII}}$, and $\mathrm{q}_{\mathrm{P}}$ were on $12 \mathrm{~d}$ of the waterlogging treatment. The $\mathrm{F}_{\mathrm{v}} / \mathrm{F}_{\mathrm{m}}, \Phi_{\mathrm{PSII}}$, and $\mathrm{q}_{\mathrm{P}}$ decreased gradually in both cultivars. After 12-d waterlogging, the $\mathrm{F}_{\mathrm{v}} / \mathrm{F}_{\mathrm{m}}, \Phi_{\text {PSII }}$, and $\mathrm{q}_{\mathrm{P}}$ were lowered by $23.6,44.1$, and $38.1 \%$, respectively, in JZ31, and by $13.9,24.0$, and $19.7 \%$, respectively, in JN01, compared with CK (Fig. 3A-C). At 3, 6, 9, and $12 \mathrm{~d}$ of the waterlogging treatment, the NPQ in JN01 was 1.09-, 1.19-, 1.39-, and 1.19-fold that in CK, respectively. In JZ31, the NPQ was higher than that in CK only at 9 and $12 \mathrm{~d}$ of the waterlogging treatment (1.15- and 1.12-fold of that in CK, respectively) (Fig. 3D).

Chloroplast ultrastructure: The results of ultrastructure

Table 1. Waterlogging effects on yield and yield components of two sorghum cultivars. Values are shown with standard deviation. Different small letters within a column indicate significant difference $(P<0.05$, Duncan's multiple range test). JN01 - waterloggingtolerant cultivar Jinuoliang01, JZ31 - waterlogging-sensitive cultivar Jinza31, CK - no waterlogging, WL - waterlogging.

\begin{tabular}{llllll}
\hline & Treatments & Number of panicles $\left[\mathrm{ha}^{-1}\right]$ & Number of grains per panicle & 1,000 -grain mass $[\mathrm{g}]$ & Grain yield $\left[\mathrm{kg} \mathrm{ha}{ }^{-1}\right]$ \\
\hline JN01 & WL & $96,101 \pm 2,274^{\mathrm{a}}$ & $1,955 \pm 163^{\mathrm{c}}$ & $24.00 \pm 0.74^{\mathrm{b}}$ & $4,507 \pm 377^{\mathrm{b}}$ \\
& CK & $97,541 \pm 2,596^{\mathrm{a}}$ & $4,885 \pm 236^{\mathrm{a}}$ & $20.08 \pm 0.52^{\mathrm{c}}$ & $9,563 \pm 439^{\mathrm{a}}$ \\
JZ31 & WL & $94,959 \pm 2,265^{\mathrm{a}}$ & $1,143 \pm 100^{\mathrm{d}}$ & $24.84 \pm 1.32^{\mathrm{b}}$ & $2,689 \pm 132^{\mathrm{c}}$ \\
& CK & $94,976 \pm 3,051^{\mathrm{a}}$ & $3,062 \pm 177^{\mathrm{b}}$ & $33.44 \pm 0.70^{\mathrm{a}}$ & $9,722 \pm 598^{\mathrm{a}}$ \\
\hline
\end{tabular}

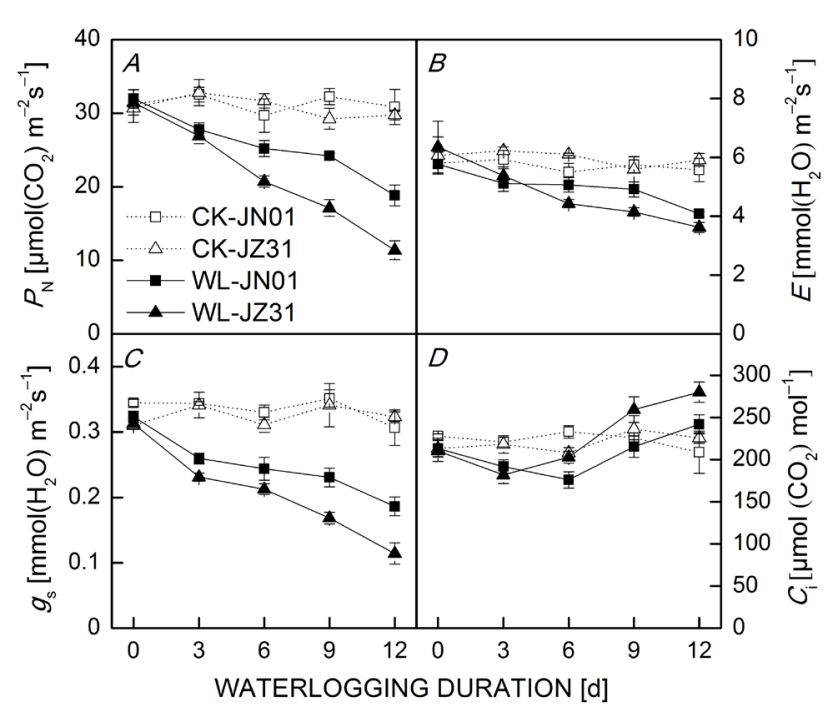

Fig. 1. Effects of waterlogging on leaf gas-exchange parameters of two sorghum cultivars: photosynthetic rate $\left(P_{\mathrm{N}}\right)(A)$, transpiration rate $(E)(B)$, stomatal conductance $\left(g_{\mathrm{s}}\right)(C)$, and intercellular $\mathrm{CO}_{2}$ concentration $\left(C_{\mathrm{i}}\right)(D)$. JN01 - waterlogging-tolerant cultivar Jinuoliang01, JZ31 - waterlogging-sensitive cultivar Jinza31, $\mathrm{CK}$ - no waterlogging, WL - waterlogging. analyses of chloroplasts in sorghum leaves under waterlogging and in CK are shown in Fig. 4 and Table 2. The CK of both cultivars had chloroplasts with normal structures. The chloroplasts were oval with a clear boundary, of typical thylakoid organization with integrated grana and stroma lamellae, the lamellae were folded in an orderly manner, and the grana and stroma lamellae were enclosed by an external envelope with a clearly visible and integrated double membrane (Fig. $4 A-C, J-L$ ). After waterlogging stress, the chloroplasts showed changes in their external morphology and internal structure, and these changes differed significantly between the two cultivars. After waterlogging for $6 \mathrm{~d}$, the chloroplasts in JZ31 were swollen and spherical, the boundary, external capsule, and grana lamellae were fuzzy and disordered, and the plastoglobuli were more abundant and larger. At the same time point, the chloroplasts in JN01 showed few changes. The chloroplasts were still oval, had clearly defined boundaries and organized thylakoids and grana lamellae, and the chloroplast structure was integrated with lamellae arranged in an orderly manner (Fig. $4 D-F, M-O$ ). After waterlogging for $12 \mathrm{~d}$, the external membrane structure and grana lamellae were degraded in chloroplasts of JZ31, and the internal spaces of the chloroplasts were filled with plastoglobuli. At the same time point, the chloroplasts in 


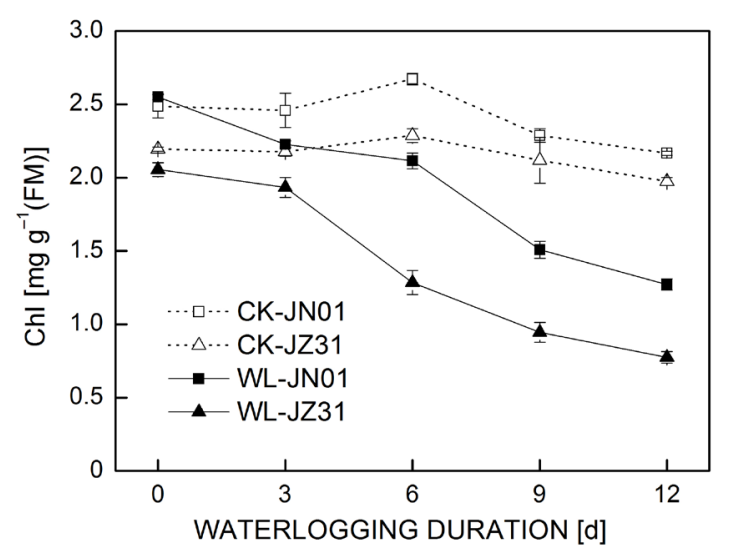

Fig. 2. Effects of waterlogging on total chlorophyll (Chl) content in the leaves of two sorghum cultivars. JN01 - waterloggingtolerant cultivar Jinuoliang01, JZ31 - waterlogging-sensitive cultivar Jinza31, CK - no waterlogging, WL - waterlogging.

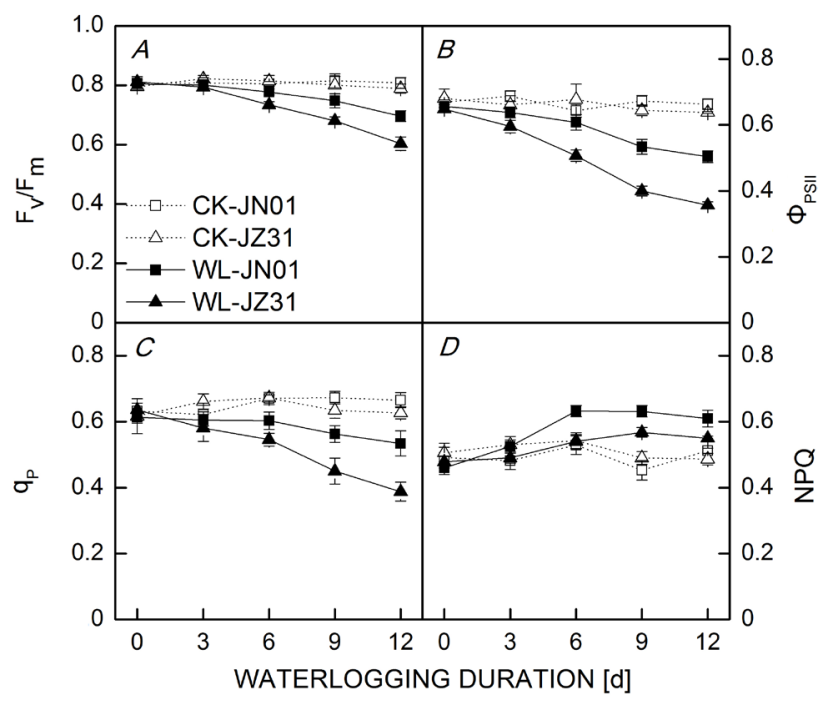

Fig. 3. Effects of waterlogging on chlorophyll fluorescence parameters in the leaves of two sorghum cultivars: maximum quantum efficiency of PSII photochemistry $\left(\mathrm{F}_{\mathrm{v}} / \mathrm{F}_{\mathrm{m}}\right)(A)$, photochemical efficiency of photosystem II $\left(\Phi_{\mathrm{PSII}}\right)(B)$, photochemical quenching coefficient $\left(\mathrm{q}_{\mathrm{P}}\right)(C)$, and nonphotochemical quenching (NPQ) $(D)$. JN01 - waterlogging-tolerant cultivar Jinuoliang01, JZ31 waterlogging-sensitive cultivar Jinza31, CK - no waterlogging, $\mathrm{WL}$ - waterlogging.

JN01 were round and the lamellae were loosely arranged (Fig. $4 G-I, P-R$ ).

To quantify the changes in chloroplasts under waterlogging, we evaluated the number and shape of chloroplasts in both cultivars. At 6 and $12 \mathrm{~d}$ of the waterlogging treatment, the numbers of chloroplast decreased by 45.5 and $60.6 \%$, respectively, in JN01, and by 50.0 and $70.0 \%$, respectively, in JZ31, compared with CK. In JN01, the length-to-width ratio of chloroplasts was significantly lowered by 23.1 and $55.2 \%$ at 6 and $12 \mathrm{~d}$ of the waterlogging treatment, respectively, compared with CK. In JZ31, the length-to-width ratio of chloroplasts was decreased by 51.9 and $63.0 \%$ at 6 and $12 \mathrm{~d}$ of the waterlogging treatment, respectively, compared with CK. At the end of the waterlogging treatment, the size of chloroplasts was reduced by $40.8 \%$ in JN01 and by $58.2 \%$ in JZ31, and the cell area occupied by chloroplasts decreased by $60.6 \%$ in JN01, and by $81.2 \%$ in JZ31, compared with CK (Table 2).

MDA and antioxidant enzyme activity: The MDA content in the sorghum leaves increased during the waterlogging treatment. The MDA in leaves of JZ31 was 1.36-, 2.28-, 2.72-, and 2.45-fold that in CK at 3, 6, 9, and $12 \mathrm{~d}$, respectively. The MDA in leaves of JN01 was 1.71-, 1.98-, 1.82-, and 1.80-fold that in $\mathrm{CK}$ at 3, 6, 9, and $12 \mathrm{~d}$, respectively (Fig. $5 A$ ). In the absence of waterlogging stress, the activity of ROS-scavenging enzymes was low. However, their activities changed significantly under waterlogging stress. The SOD activity increased in both cultivars under waterlogging stress. The SOD activity in leaves of JN01 was 1.40-, 1.51-, 1.46-, and 1.38-fold that in $\mathrm{CK}$ at 3, 6, 9, and $12 \mathrm{~d}$, respectively, while that in leaves of JZ31 was 1.18-, 1.29-, 1.47-, and 1.50-fold that in CK at $3,6,9$, and $12 \mathrm{~d}$, respectively (Fig. 5B). The POD activity was greater in JN01 than that in JZ31. It increased by $3 \mathrm{~d}$ of the waterlogging treatment, peaked at $9 \mathrm{~d}$ (at 2.14fold that in CK), and then decreased by $12 \mathrm{~d}$. The POD activity in JZ31 was lower than that in CK except at $6 \mathrm{~d}$ of the waterlogging treatment (Fig. 5C). The CAT activity differed significantly between the two cultivars and was higher in JN01 than that in JZ31. The CAT activity in JN01 was 1.89-, 2.19-, 1.21-, and 1.43-fold that in CK at 3, 6, 9, and $12 \mathrm{~d}$, respectively, while that in JZ31 was 0.98-, 1.58-, 1.08-, and 1.36-fold that in CK 3, 6, 9, and $12 \mathrm{~d}$ of the waterlogging treatment, respectively (Fig. $5 D$ ).

\section{Discussion}

The effects of waterlogging on plant growth and development have attracted much attention, especially in the context of global climate change (Du et al. 2016, Wang et al. 2017, Xu et al. 2018). Waterlogging usually causes plant leaves to wilt and develop chlorosis (Arbona et al. 2010). The decreased Chl content results in a decrease in $P_{\mathrm{N}}$, which ultimately decreases yield. In the present study, both cultivars showed significant yield reductions in response to the waterlogging, but the yield loss was greater in JZ31 than that in JN01 (Table 1). The significant decrease in the grain yield resulted from a reduction in the number of grains per panicle, indicating that waterlogging affected panicle differentiation and the seed-setting rate. Consistent with this result, Ren et al. (2016) reported that waterlogging damaged maize endosperm cell proliferation and reduced the number of grains per ear, resulting in a significant reduction in grain yield. The effects of waterlogging on 1,000-grain mass differed between the two cultivars. The 1,000-grain mass increased in JN01, but decreased in JZ31. Abiotic stresses usually restrain the crop growth and decrease grain yield, however, there are some compensating effects in some crops, and the effects vary in cultivars (Wang et al. 2014). The 1,000-grain mass elevated in JN01 might be a compensation for the reduction in the number of grains per panicle. Crop yield 


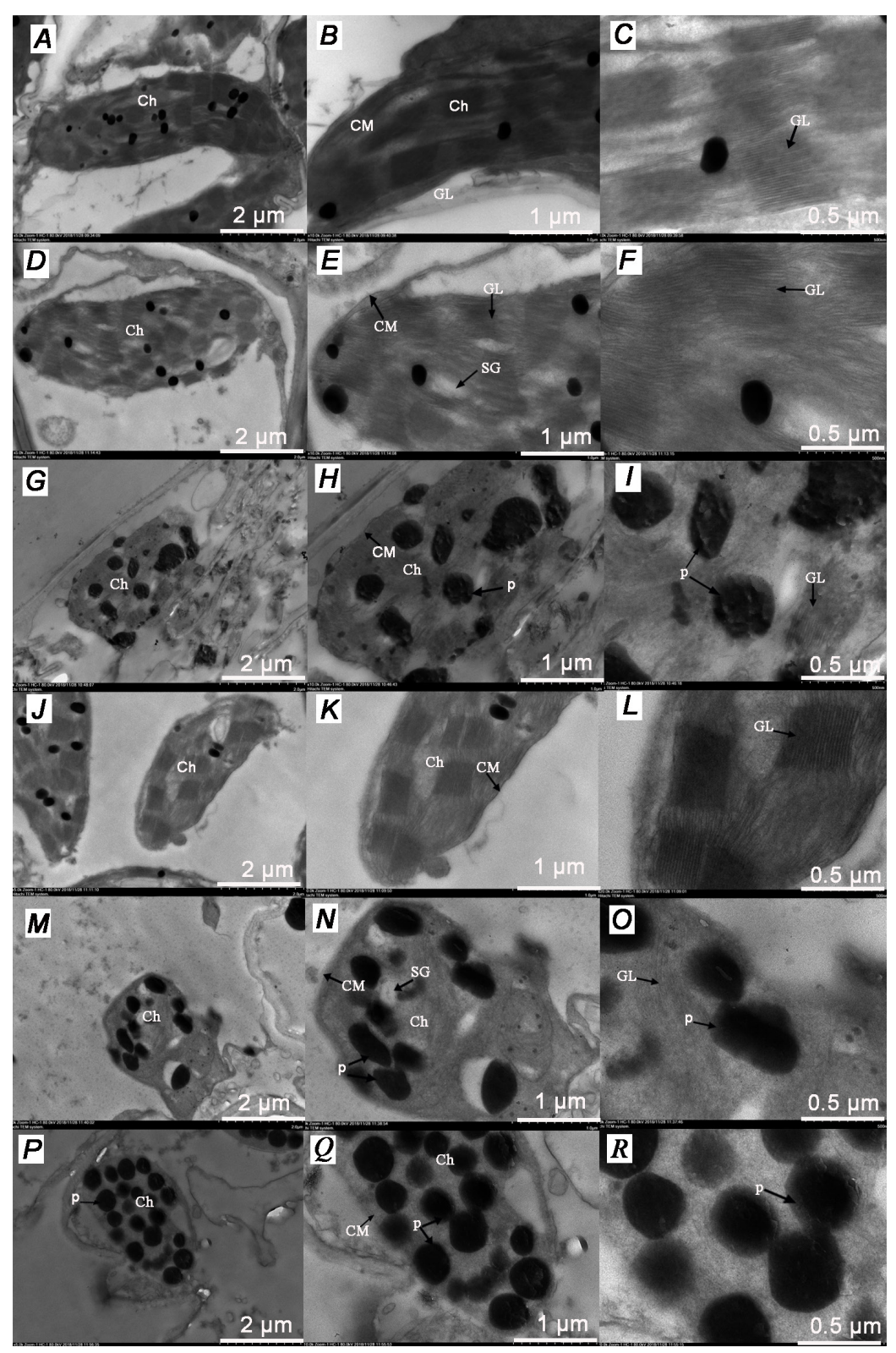

Fig. 4. Effects of waterlogging on chloroplast ultrastructure. $(A),(B)$, and $(C)$ ultrastructure of chloroplast in control Jinuoliang01 (JN01). (D), $(E)$, and $(F)$ ultrastructure of chloroplast in JN01 at $6 \mathrm{~d}$ of waterlogging treatment. $(G),(H)$, and (I) ultrastructure of chloroplast in JN01 at $12 \mathrm{~d}$ of waterlogging treatment. $(J),(K)$, and $(L)$ ultrastructure of chloroplast in control Jinza31 (JZ31). $(M),(N)$, and $(O)$ ultrastructure of chloroplast of JZ31 at $6 \mathrm{~d}$ of waterlogging treatment. $(P),(Q)$, and $(R)$ ultrastructure of chloroplast of JZ31 at $12 \mathrm{~d}$ of waterlogging treatment. $\mathrm{Ch}-$ chloroplast, $\mathrm{CM}$ - chloroplast membrane, GL - grana lamellae, SG - starch grains, $\mathrm{P}$ - plastoglobuli.

Table 2. Waterlogging effects on morphology and ultrastructure of chloroplasts in JN01 and JZ31 sorghum cultivars. Values are shown with standard deviation. Different small letters within a column indicate significant difference $(P<0.05$, Duncan's multiple range test). JN01 - waterlogging-tolerant cultivar Jinuoliang01, JZ31 - waterlogging-sensitive cultivar Jinza31, CK - no waterlogging, WL-6 waterlogging for $6 \mathrm{~d}$; WL-12 - waterlogging for $12 \mathrm{~d}$.

\begin{tabular}{lllllll}
\hline Cultivar & Treatment & $\begin{array}{l}\text { Number of chloroplasts } \\
\text { per mesophyll cell }\end{array}$ & $\begin{array}{l}\text { Average length of } \\
\text { chloroplast }[\mu \mathrm{m}]\end{array}$ & $\begin{array}{l}\text { Average width of } \\
\text { chloroplast }[\mu \mathrm{m}]\end{array}$ & $\begin{array}{l}\text { Length-to-width ratio } \\
\text { of chloroplasts }\end{array}$ & $\begin{array}{l}\text { Cell area occupied } \\
\text { by chloroplasts [\%] }\end{array}$ \\
\hline $\mathrm{JN} 01$ & $\mathrm{CK}$ & $6.60 \pm 0.89^{\mathrm{a}}$ & $6.06 \pm 0.42^{\mathrm{a}}$ & $1.72 \pm 0.18^{\mathrm{bc}}$ & $3.55 \pm 0.49^{\mathrm{a}}$ & $49.32 \pm 4.32^{\mathrm{a}}$ \\
& WL-6 & $3.60 \pm 0.89^{\mathrm{b}}$ & $5.05 \pm 0.5^{\mathrm{b}}$ & $1.87 \pm 0.21^{\mathrm{ab}}$ & $2.73 \pm 0.42^{\mathrm{b}}$ & $29.21 \pm 2.06^{\mathrm{b}}$ \\
& WL-12 & $2.60 \pm 0.55^{\mathrm{bc}}$ & $3.22 \pm 0.2^{\mathrm{c}}$ & $2.04 \pm 0.14^{\mathrm{a}}$ & $1.58 \pm 0.06^{\mathrm{c}}$ & $19.42 \pm 3.39^{\mathrm{c}}$ \\
$\mathrm{JZ31}$ & $\mathrm{CK}$ & $7.20 \pm 0.84^{\mathrm{a}}$ & $5.02 \pm 0.22^{\mathrm{b}}$ & $1.60 \pm 0.30^{\mathrm{c}}$ & $3.22 \pm 0.55^{\mathrm{ab}}$ & $46.94 \pm 4.61^{\mathrm{a}}$ \\
& WL-6 & $3.60 \pm 0.55^{\mathrm{b}}$ & $2.97 \pm 0.31^{\mathrm{c}}$ & $1.92 \pm 0.07^{\mathrm{ab}}$ & $1.55 \pm 0.21^{\mathrm{c}}$ & $19.63 \pm 1.35^{\mathrm{c}}$ \\
& WL-12 & $1.80 \pm 0.84^{\mathrm{c}}$ & $2.32 \pm 0.33^{\mathrm{d}}$ & $1.96 \pm 0.18^{\mathrm{ab}}$ & $1.19 \pm 0.18^{\mathrm{c}}$ & $8.84 \pm 0.57^{\mathrm{d}}$ \\
\hline
\end{tabular}




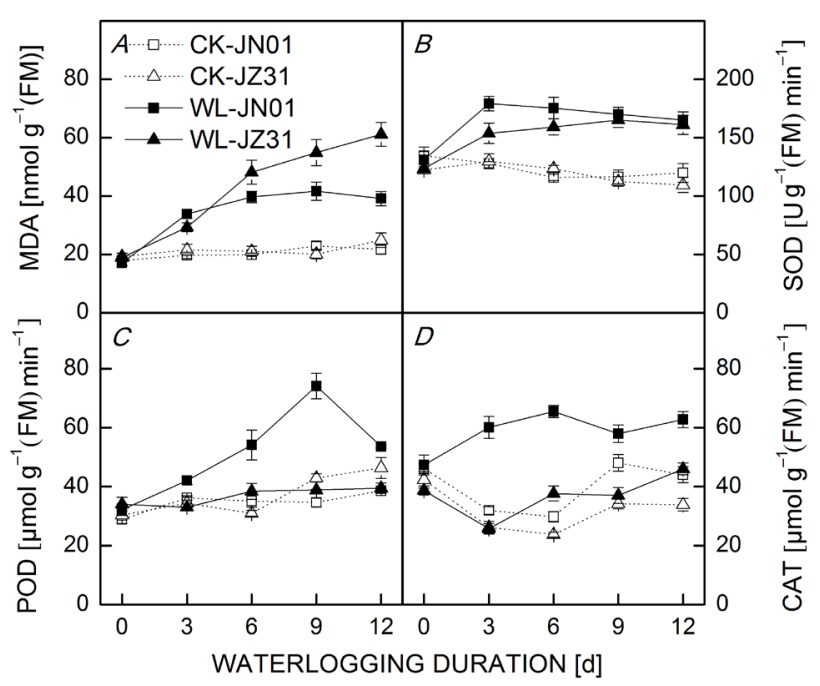

Fig. 5. Effects of waterlogging on malondialdehyde content and antioxidant enzyme activity in the leaves of two sorghum cultivars: malondialdehyde content (MDA) $(A)$, superoxide dismutase $(\mathrm{SOD})(B)$, peroxidase $(\mathrm{POD})(C)$, and catalase $(\mathrm{CAT})(D)$. JN01 - waterlogging-tolerant cultivar Jinuoliang01, JZ31 waterlogging-sensitive cultivar Jinza31, CK - no waterlogging, $\mathrm{WL}$ - waterlogging.

represents the accumulation of photosynthetic products, but photosynthesis is sensitive to waterlogging stress (Ashraf and Harris 2013). Stomatal closure is one of the earliest responses to waterlogging stress (Ahmed et al. 2002). This prevents $\mathrm{CO}_{2}$ from entering the leaf and results in a reduction in photosynthetic carbon assimilation. In this study, the $P_{\mathrm{N}}, g_{\mathrm{s}}$, and $E$ decreased at the beginning of the waterlogging treatment (Fig. 1). The decrease in $g_{\text {s }}$ and $E$ suggested that the channel for water and $\mathrm{CO}_{2}$ exchange was restricted, at the same time, the $C_{\mathrm{i}}$ also decreased, indicating that stomatal factors were mainly responsible for the decrease in photosynthesis at the early stage of waterlogging. Consistent with this result, Zheng et al. (2009) found that the decreased $P_{\mathrm{N}}$ in wheat at the early stage of waterlogging stress was associated with stomatal closure. During the waterlogging treatment, the $C_{\mathrm{i}}$ increased at $6 \mathrm{~d}$ in JZ31 and at $9 \mathrm{~d}$ in JN01. According to $\mathrm{Xu}$ (1997), when the $g_{\mathrm{s}}$ decreases and the $C_{\mathrm{i}}$ increases, the $P_{\mathrm{N}}$ decreases due to nonstomatal factors. Therefore, this result demonstrated that nonstomatal factors mainly inhibited photosynthesis in sorghum at the later stages of waterlogging. At the same time, $\mathrm{F}_{\mathrm{v}} / \mathrm{F}_{\mathrm{m}}, \Phi_{\mathrm{PSII}}$, and $\mathrm{q}_{\mathrm{P}}$ decreased significantly, suggesting that some malfunctions in the electron transport capacity of PSII led to the reduction in photosynthetic capacity. Compared with JZ31, JN01 showed higher $\mathrm{F}_{\mathrm{v}} / \mathrm{F}_{\mathrm{m}}, \Phi_{\mathrm{PSII}}, \mathrm{q}_{\mathrm{P}}$, and $\mathrm{Chl}$ content, and a more rapid increase in NPQ. These results indicated that the lower degree of injury in the insensitive cultivar was due to greater protection of PSII under waterlogging stress. Luan et al. (2018) reported similar results for barley.

We observed that the chloroplast membrane dissolved and the boundary of the basal layer became indistinct in leaves of sorghum under waterlogging stress (Fig. 4). However, the chloroplast structure remained more stable in JN01 than that in JZ31. Even though the grana lamellae were occasionally visible in JN01, they were almost fully degraded in JZ31 at the end of the waterlogging treatment. These observations indicated that the chloroplast structure was less damaged, and remained more stable, in JN01 than in JZ31. Previous studies have shown that most of the damage to chloroplast structure is caused by reactive oxygen species (ROS) (Ren et al. 2016, Ma et al. 2017, Zhou et al. 2018). Nevertheless, chloroplasts can be a major source of ROS (Maruta et al. 2012). Waterlogging can trigger excessive accumulation of photosynthetic energy, resulting in electron leakage from the photosynthetic electron transport chain. These leaked electrons can combine with redundant $\mathrm{O}_{2}$ to produce superoxide anions $\left(\mathrm{O}_{2}^{-}\right)$, which give rise to hydroxyl radicals $\left(\mathrm{OH}^{\circ}\right)$ and hydrogen peroxide $\left(\mathrm{H}_{2} \mathrm{O}_{2}\right)$ (Zheng et al. 2017). The membrane structure can be damaged by ROS that accumulate under waterlogging (Ren et al. 2016).

Yordanova et al. (2004) suggested that high antioxidant enzyme activity could improve plant waterlogging tolerance. We found that the activities of antioxidant enzymes increased under waterlogging, and increased more in the tolerant cultivar JN01 than in the sensitive cultivar, JZ31. In both cultivars, SOD activity increased at $3 \mathrm{~d}$ of waterlogging and remained high throughout the treatment. The activities of POD and CAT changed differently in the two cultivars under waterlogging. The CAT and POD activities were higher in JN01 than that in JZ31. Because POD and CAT can efficiently scavenge $\mathrm{H}_{2} \mathrm{O}_{2}$, they could be the key antioxidant enzymes in JN01 to protect the chloroplast against damage from excess ROS under waterlogging stress.

In summary, waterlogging reduced the $P_{\mathrm{N}}$ and damaged chloroplast structure in sorghum leaves, resulting in decreased yields in both waterlogging-tolerant and waterlogging-sensitive cultivar. Compared to the sensitive cultivar JZ31, the tolerant cultivar JN01 retained a more stable chloroplast structure and suffered less damage under waterlogging. The high NPQ and increased activities of antioxidant enzymes (POD and CAT) were important factors in protecting the chloroplast structure and maintaining higher $P_{\mathrm{N}}$ in the waterlogging-tolerant cultivar. These results provide details of the waterlogging resistance mechanisms of sorghum and provide a reference for the breeding of waterlogging-resistant sorghum varieties.

\section{References}

Ahmed S., Nawata E., Hosokawa M. et al.: Alterations in photosynthesis and some antioxidant enzymatic activities of mungbean subjected to waterlogging. - Plant Sci. 163: 117-123, 2002.

Arbona V., Hossain Z., López-Climent M. F. et al.: Antioxidant enzymatic activity is linked to waterlogging stress tolerance in citrus. - Physiol. Plantarum 132: 452-466, 2010.

Arguello M.N., Mason R.E., Roberts T.L. et al.: Performance of soft red winter wheat subjected to field soil waterlogging: Grain yield and yield components. - Field Crop. Res. 194: 57-64, 2016.

Ashraf M., Harris P.J.C.: Photosynthesis under stressful environments: An overview. - Photosynthetica 51: 163-190, 2013. 
Bansal R., Srivastava J.P.: Effect of waterlogging on photosynthetic and biochemical parameters in pigeonpea. Russ. J. Plant Physl+ 62: 322-327, 2015.

Du H., Huang M., Liu L.: The genome wide analysis of GT transcription factors that respond to drought and waterlogging stresses in maize. - Euphytica 208: 113-122, 2016.

Fielding J.L., Hall J.L.: A biochemical and cytochemical study of peroxidase activity in roots of Pisum sativum: I. A comparison of DAB-peroxidase and guaiacol-peroxidase with particular emphasis on the properties of cell wall activity. - J. Exp. Bot. 29: 969-981, 1978 .

Hazrati S., Tahmasebi-Sarvestani Z., Modarres-Sanavy S.A.M. et al.: Effects of water stress and light intensity on chlorophyll fluorescence parameters and pigments of Aloe vera L. - Plant Physiol. Bioch. 106: 141-148, 2016.

Herzog M., Striker G.G., Colmer T.D., Pedersen O.: Mechanisms of waterlogging tolerance in wheat. A review of root and shoot physiology. - Plant Cell Environ. 39: 1068-1086, 2016.

Jahns P., Holzwarth A.R.: The role of the xanthophyll cycle and of lutein in photoprotection of photosystem II. BBA-Bioenergetics 1817: 182-193, 2012.

Lichtenthaler H.K.: Chlorophylls and carotenoids: pigments of photosynthetic biomembranes. - Method. Enzymol. 148: 350-382, 1987.

Lin H.H., Lin K.H., Syu J.Y. et al.: Physiological and proteomic analysis in two wild tomato lines under waterlogging and high temperature stress. - J. Plant Biochem. Biot. 25: 87-96, 2016.

Luan H., Guo B., Pan Y. et al:: Morpho-anatomical and physiological responses to waterlogging stress in different barley (Hordeum vulgare L.) genotypes. - Plant Growth Regul. 85: 399-409, 2018.

Ma J., Lv C.F., Zhang B.B. et al:: Comparative analysis of ultrastructure, antioxidant enzyme activities, and photosynthetic performance in rice mutant $812 \mathrm{HS}$ prone to photooxidation. - Photosynthetica 55: 568-578, 2017.

Maruta T., Noshi M., Tanouchi A. et al.: $\mathrm{H}_{2} \mathrm{O}_{2}$-triggered retrograde signaling from chloroplasts to nucleus plays specific role in response to stress. - J. Biol. Chem. 287: 11717-11729, 2012.

Mathobo R., Marais D., Steyn J.M.: The effect of drought stress on yield, leaf gaseous exchange and chlorophyll fluorescence of dry beans (Phaseolus vulgaris L.). - Agr. Water Manage. 180: 118-125, 2017.

Pereira T.S., Lobato A.K.S., Alves G.A.R. et al.: Tolerance to waterlogging in young Euterpe oleracea plants. Photosynthetica 52: 186-192, 2014.

Promkhambut A., Younger A., Polthanee A., Akkasaeng C.: Morphological and physiological responses of sorghum (Sorghum bicolor L. Moench) to waterlogging. - Asian J. Plant Sci. 9: 183-193, 2010.

Ren B., Zhang J., Dong S. et al.: Effects of waterlogging on leaf mesophyll cell ultrastructure and photosynthetic characteristics of summer maize. - PLoS ONE 11: e0161424, 2016.

Setter T.L., Waters I.: Review of prospects for germplasm improvement for waterlogging tolerance in wheat, barley and oats. - Plant Soil 253: 1-34, 2003.

Shabala S.: Physiological and cellular aspects of phytotoxicity tolerance in plants: The role of membrane transporters and implications for crop breeding for waterlogging tolerance. New Phytol. 190: 289-298, 2011.

Shao G.C., Lan J.J., Yu S.E. et al.: Photosynthesis and growth of winter wheat in response to waterlogging at different growth stages. - Photosynthetica 51: 429-437, 2013.
Shao R.X., Xin L.F., Zheng H.F. et al.: Changes in chloroplast ultrastructure in leaves of drought-stressed maize inbred lines. - Photosynthetica 54: 74-80, 2016.

Tan W., Liu J., Dai T. et al.: Alterations in photosynthesis and antioxidant enzyme activity in winter wheat subjected to postanthesis water-logging. - Photosynthetica 46: 21-27, 2008.

Van Kooten O., Snel J.F.H.: The use of chlorophyll fluorescence nomenclature in plant stress physiology. - Photosynth. Res. 25: 147-150, 1990.

Wang N., Liu J., Zhou Y.F.: Structural responses of vascular bundles in different maize stems to water deficit during seedling stage: A compensating development. - Res. Crop. 15: 532-538, 2014

Wang X., Deng Z., Zhang W. et al.: Effect of waterlogging duration at different growth stages on the growth, yield and quality of cotton. - PLoS ONE 12: e0169029, 2017.

Wright A.J, de Kroon H., Visser E.J.W. et al.: Plants are less negatively affected by flooding when growing in species-rich plant communities. - New Phytol. 213: 645-656, 2017.

Xu D.Q.: [Some problems in stomatal limitation analysis of photosynthesis.] - Plant Physiol. Commun. 33: 241-244, 1997. [In Chinese]

$\mathrm{Xu}$ X., Ji J., Xu Q. et al.: The major-effect QTL CsARN6.1 encodes an AAA-ATPase domain-containing protein that is associated with waterlogging stress tolerance through promoting adventitious root formation. - Plant J. 93: 917-930, 2018.

Yin D., Chen S., Chen F. et al.: Morphological and physiological responses of two chrysanthemum cultivars differing in their tolerance to waterlogging. - Environ. Exp. Bot. 67: 87-93, 2009.

Yordanova R.Y., Christov K.N., Popova L.P.: Antioxidative enzymes in barley plants subjected to soil flooding. - Environ. Exp. Bot. 51: 93-101, 2004.

Yu B., Zhao C.Y., Li J. et al:: Morphological, physiological, and biochemical responses of Populus euphratica to soil flooding. - Photosynthetica 53: 110-117, 2015.

Zhang G., Tanakamaru K., Abe J., Morita S.: Influence of waterlogging on some anti-oxidative enzymatic activities of two barley genotypes differing in anoxia tolerance. - Acta Physiol. Plant. 29: 171-176, 2007.

Zhang Y., Chen Y., Lu H. et al.: Growth, lint yield and changes in physiological attributes of cotton under temporal waterlogging. - Field Crop. Res. 194: 83-93, 2016.

Zhao D., Oosterhuis D.M., Bednarz C.W.: Influence of potassium deficiency on photosynthesis, chlorophyll content, and chloroplast ultrastructure of cotton plants. - Photosynthetica 39: 103-109, 2001.

Zheng C., Jiang D., Liu F. et al.: Effects of salt and waterlogging stresses and their combination on leaf photosynthesis, chloroplast ATP synthesis, and antioxidant capacity in wheat. Plant Sci. 176: 575-582, 2009.

Zheng X., Zhou J., Tan D.X. et al.: Melatonin improves waterlogging tolerance of Malus baccata (Linn.) Borkh. seedlings by maintaining aerobic respiration, photosynthesis and ROS migration. - Front. Plant Sci. 8: 483, 2017.

Zhou Y.W., Chen J.H., Lu L. et al.: [Changes on leaf chloroplast ultrastructure and photosynthetic characteristics of Liriodendron sino-americanum somatic embryo regeneration seedlings under waterlogging stress.] - Sci. Silva. Sin. 54: 19-28, 2018. [In Chinese]

Zhu M., Li F.H., Shi Z.S.: Morphological and photosynthetic response of waxy corn inbred line to waterlogging. Photosynthetica 54: 636-640, 2016.

(C) The authors. This is an open access article distributed under the terms of the Creative Commons BY-NC-ND Licence. 